\title{
Solving of Some Random Partial Differential Equations by Using Differential Transformation Method and Laplace- Padé Method
}

\author{
Bazı Rastgele Kısmi Diferansiyel Denklemlerin Diferansiyel Dönüşüm Metodu ve Laplace- \\ Padé Metodu Kullanarak Çözümü
}

\author{
Mehmet MERDAN ${ }^{1, a}$, Halil ANAÇ*1,b ${ }^{*}$ Zafer BEKİRYAZICI ${ }^{2, c}$, Tülay KESEMEN ${ }^{3, d}$ \\ ${ }^{I}$ Gümüşhane University, Faculty of Engineering and Natural Sciences, Department of Mathematical Engineering, 29100, Gümüshane \\ ${ }^{2}$ Recep Tayyip Erdogan University, Faculty of Arts and Sciences, Department of Mathematics, 53100, Rize \\ ${ }^{3}$ Karadeniz Technical University, Faculty of Science, Department of Mathematics, 61080, Trabzon
}

• Geliş tarihi / Received: 12.03.2018 • • Düzeltilerek geliş tarihi / Received in revised form: 22.06 .2018 • Kabul tarihi / Accepted: 27.06 .2018

\begin{abstract}
In this study, the solutions of random partial differential equations are examined. The parameters and the initial conditions of the random component partial differential equations are investigated with Beta distribution. A few examples are given to illustrate the efficiency of the solutions obtained with the random Differential Transformation Method (rDTM). Functions for the expected values and the variances of the approximate analytical solutions of the random equations are obtained. Random Differential Transformation Method is applied to examine the solutions of these partial differential equations and MAPLE software is used for the finding the solutions and drawing the figures. Also the Laplace- Padé Method is used to improve the convergence of the solutions. The results for the random component partial differential equations with Beta distribution are analysed to investigate effects of this distribution on the results. Random characteristics of the equations are compared with the results of the deterministic partial differential equations. The efficiency of the method for the random component partial differential equations is investigated by comparing the formulas for the expected values and variances with results from the simulations of the random equations.
\end{abstract}

Keywords: Expected Value, Random Component Partial Differential Equation, Random Differential Transformation Method

$\ddot{O} z$

Bu çalışmada, rastgele kısmi diferansiyel denklemlerin çözümleri incelenmiştir. Rastgele bileşenli kısmi diferansiyel denklemlerin başlangıç şartları ve parametreleri Beta dağıllımı ile incelenmiştir. Rastgele Diferansiyel dönüşüm yöntemi ile elde edilen çözümlerin etkinliği birkaç örnekle verilmiştir. Rastgele denklemlerin yaklaşı analitik çözümlerinin beklenen değerleri ve varyansları için fonksiyonlar elde edilmiştir. Rastgele Diferansiyel dönüşüm yöntemi, bu kısmi diferansiyel denklemlerin çözümlerini incelemek için uygulanmış ve MAPLE programı, çözümleri bulmak ve grafikleri çizmek için kullanılmıştır. Ayrıca çözümlerin yakınsaklı̆̆ın iyileştirmek için Laplace-Padé metodu kullanılmıştır. Beta dağıllmı ile rastgele bileşenli kısmi diferansiyel denklemlerin sonuçları, bu dağgllımın sonuçlara etkilerini incelemek amacıyla analiz edilmiştir. Denklemlerin rastgele karakteristikleri ile rastgele olmayan kismi diferansiyel denklemlerin sonuçları karş̧laş̧tırllmıştır. Rastgele bileşenli kısmi diferansiyel denklemler için yöntemin etkinliği, rastgele denklemlerin simülasyonlarından elde edilen sonuçlarla beklenen değerlerin ve varyansların formüllerini karşılaştırarak incelenmiştir. MAPLE programı, rastgele bileşenli kısmi diferansiyel denklemlerin sonuçlarını simüle etmek için kullanılmıştır ve bu simülasyon sonuçlarından standart sapma, güven aralı̆̆ gibi diğer karakteristiklerler elde edilmiştir.

Anahtarlar kelimeler: Beklenen değer, Rastgele bileşenli kısmi diferansiyel denklemler, Rastgele diferansiyel dönüşüm metodu

\footnotetext{
*b Halil ANAÇ; halilanac@gumushane.edu.tr; Tel: (0456) 23310 00; orcid.org/0000-0002-1316-3947

${ }^{a}$ orcid.org/0000-0002-8509-3044 ${ }^{c}$ orcid.org/0000-0001-5671-9995 orcid.org/0000-0002-8807-5677
} 


\section{Introduction}

Random ordinary differential equations are currently being studied extensively. Two dimensional random differential equations have a great significance in many applications in areas such as engineering, biology and physics. Models of various scientific problems are established with nonlinear random differential equations containing two variables. Many of these equations can be analyzed by numerical methods. A few of these numerical methods are Homotopy Perturbation Method (HPM) (Khalaf, 2011), Adomian Decomposition Method (ADM) (Khudair et al, 2011) and Variational Iteration Method (VIM) (Khudair et al, 2011).

In 2012, L. Villafuerte and B.M. ChenCharpentier developed the random differential transformation method to solve random differential equations. They found an analytical mean-fourth convergent series solution to a nonlinear random Riccati differential equation with the random DTM. In addition, they obtained approximate values of the basic statistical functions of the random solution process such as the mean and variance by using this series solution of the Riccati equation (Villafuerte and Chen-Charpentier, 2012).

The goal of this study is to present the application of differential transformation method (DTM) for obtaining variance and expected values of accurate and approximate solutions of the random component partial differential equations. For this aim, the notion of the two dimensional differential transformation method is given in Section 1.1. Laplace-Padé method is given in Section 1.2. Beta distribution and its properties such as the probability density function, expected value and variance are introduced in Section 1.3. Some applications are given in Section 2.

\subsection{Two-dimensional differential transformation method}

Let $w(x, y)$ be analytic and differentiated continuously in the domain of interest. $W(k, h)$ is defined as follows ( Kanth and Aruna, 2009; Kangalgil and Ayaz, 2009; Yüzbaşi and Ismailov, 2017; Tari et al, 2009; Ziyaee and Tari, 2015; Hadizadeh and Moatamedi, 2007;Zhou, 1986).

$W(k, h)=\frac{1}{k ! h !}\left[\frac{\partial^{k+h} w(x, y)}{\partial x^{k} \partial y^{h}}\right]_{\left(x_{0}, y_{0}\right)}$ (where the $W(k, h)$ is the transformed function, i.e. T-function). In this study, $w(x, y)$ will indicate the original function and $W(k, h)$ will indicate the transformed function (T-function). The differential inverse transform of $W(k, h)$ is defined as follows:

$$
\begin{aligned}
& w(x, y)=\sum_{k=0}^{\infty} \sum_{h=0}^{\infty} W(k, h)\left(x-x_{0}\right)^{k}(y- \\
& \left.y_{0}\right)^{h}
\end{aligned}
$$

Using (1) and (2), it is found that

$$
\begin{aligned}
& w(x, y)=\sum_{k=0}^{\infty} \sum_{h=0}^{\infty} \frac{1}{k ! h !}\left[\frac{\partial^{k+h} w(x, y)}{\partial^{k} \partial^{h}}\right]_{\left(x_{0}, y_{0}\right)}(x- \\
& \left.x_{0}\right)^{k}\left(y-y_{0}\right)^{h}
\end{aligned}
$$

The notion of the two-dimensional differential transform can be found with the basis of twodimensional Taylor series expansion. From (1) and (2), the basic operations obtained by two dimensional differential transform are given in Table1 (Jang et al, 2001; Bildik et al, 2006; Pukhov, 1982).

We give the Laplace-Padé method to expand the convergence region of the series solutions obtained by random DTM in the following.

\subsection{Laplace-Padé Method}

Consider the power series $\sum_{k=0}^{\infty} a_{k} x^{k}$. Assume that $f(x)$ represents a function such that

$f(x)=\sum_{k=0}^{\infty} a_{k} x^{k}$

A Padé approximation is defined as follows. (Merdan, 2010; Abassy et al, 2007)

$\left[\frac{L}{M}\right]=\frac{P_{L}(x)}{Q_{M}(x)}=\frac{p_{L} x^{L}+\ldots+p_{1} x+p_{0}}{q_{M} x^{M}+\ldots+q_{1} x+q_{0}}$

The Padé approximation can be obtained from Maclaurin expansion which complies with (4). There are $(L+1)$ dividend coefficients and $(M+1)$ divisor coefficients in formula (5). 
Table1: Operations in the two-dimensional differential transform

\begin{tabular}{|c|c|}
\hline Original function & Transformed function \\
\hline$w(x, y)=u(x, y) \pm v(x, y)$ & $W(k, h)=U(k, h) \pm V(k, h)$ \\
\hline$w(x, y)=\alpha u(x, y)$ & $W(k, h)=\alpha U(k, h)$ \\
\hline$w(x, y)=\frac{\partial u(x, y)}{\partial x}$ & $W(k, h)=\frac{(k+1)}{H} U(k+1, h)$ \\
\hline$w(x, y)=\frac{\partial u(x, y)}{\partial y}$ & $W(k, h)=\frac{(k+1)}{K} U(k, h+1)$ \\
\hline$w(x, y)=\frac{\partial^{r+s} u(x, y)}{\partial^{r} \partial^{s}}$ & $W(k, h)=\frac{[(k+1)(k+2) \ldots(k+r)(h+1)(h+2) \ldots(h+s) \ldots U(k+r, h+s)]}{\left(H^{r} K^{s}\right)}$ \\
\hline$w(x, y)=u(x, y) v(x, y)$ & $W(k, h)=U(k, h) \otimes V(k, h)$ \\
& $=\sum_{r=0}^{k} \sum_{s=0}^{h} U(r, h-s) V(k-r, s)$ \\
\hline$w(x, y)=x^{m} y^{n}$ & \\
\hline
\end{tabular}

The polynomials in (5) are constituted so that $f(x)$ and $\left[\frac{L}{M}\right]$ conform at $x=0$ and their derivatives up to $L+M$ conform at $x=0$. Under the condition $Q_{0}(x)=1$, the approximation is exactly the Maclaurin expansion for $f(x)$. In the case $L+M$ is a fixed value, when $P_{L}(x)$ and $Q_{M}(x)$ get the same degree or the degree of $P_{L}(x)$ gets one bigger than the degree of $Q_{M}(x)$, the error is smallest. Pay attention that the constant coefficient of $Q_{M}$ is $q_{0}=1$. When both $P_{L}(x)$ and $Q_{M}(x)$ are divided by the same

$\sum_{k=0}^{\infty} a_{k} x^{k} \frac{P_{L}(x)}{Q_{M}(x)}=\frac{p_{L} x^{L}+\ldots+p_{1} x+p_{0}}{q_{M} x^{M}+\ldots+q_{1} x+q_{0}}+O\left(x^{L+M+1}\right)$.

$a_{s}+\sum_{i=1}^{M} a_{s-i} q_{i}=p_{s},(s=0, \ldots, M)$

$a_{s}+\sum_{i=1}^{L} a_{s-i} q_{i}=0,(s=M+1, \ldots, M+L)$.

If we solve the linear equation in (8), we obtain $q_{i}(i=1, \ldots, L)$. If we replace $q_{i}$ in (7), we obtain $q_{s}(s=0,1, \ldots, M)$. Hence, we constitute a $\left[\frac{L}{M}\right]$ Pade approximation that conforms by $\sum_{k=0}^{\infty} a_{k} x^{k}$ along order $x^{L+M}$. When $M \leq L \leq M+2$ where $L$ and $M$ are respectively the degree of divisor and dividend in Padé series, an invariable formula for an ordinary differential equation is obtained by Padé series. (Abassy et al, 2007) constant, $\left[\frac{L}{M}\right]$ remains unchanged. So the rational function $\left[\frac{L}{M}\right]$ gets $(L+M+1)$ unknown coefficients. This number offers that the $\left[\frac{L}{M}\right]$ must accord the power series (4) along the orders $1, x, x^{2}, \ldots, x^{L+M}$ in the symbol of formal power series,

We multiply the both side of (6) with the divisor of right side in (6) and contrast the coefficients of both sides in (6). We obtain (7) and (8).

\subsection{Beta Distribution}

In 1895, a Beta function was used to explain the Beta distribution introduced by Karl Pearson, and the use of this function gives the Beta distribution. We use the standard state of Beta distribution in this paper.

Definition (Beta random variable): If the probability density of a random variable $X$ has the following form, this random variable has the Beta 
distribution and is called a Beta random variable. For $\alpha, \beta>0$ and $0<x<1$,

$\mathrm{f}(x, \alpha, \beta)=\frac{\Gamma(\alpha+\beta)}{\Gamma(\alpha) \Gamma(\beta)} x^{\alpha-1}(1-x)^{\beta-1}$

If the random variable $X$ gets a beta distribution with parameters $\alpha$ and $\beta$, the expected value and variance of the random variable $X$ are given as (Eugene et al, 2002):

$E(X)=\frac{\alpha}{\alpha+\beta}, \operatorname{Var}(X)=\frac{\alpha \beta}{(\alpha+\beta)^{2}(\alpha+\beta+1)}$
In this study, Beta distribution in the used examples is taken as $\operatorname{Beta}(\alpha=2, \beta=1)$. Also the symbol of $u_{a}(x, t)$ indicates approximate solutions of the following equations.

\section{Applications}

Example 1. Consider the following convectiondiffussion equation

$$
\frac{\partial u}{\partial t}=\frac{\partial^{2} u}{\partial x^{2}}-\frac{\partial u}{\partial x}+u \frac{\partial^{2} u}{\partial x^{2}}-u^{2}+u
$$

with the initial-value conditions for $a>0$ and let $a$ be random variable with beta distribution. Let these initial-value conditions be random:

$u(x, 0)=a e^{x}, u(0, t)=a e^{t}, u_{t}(x, 0)=a e^{x}, u_{x}(0, t)=a e^{t}$

Applying the differential transform of (11), it can be found that

$(h+1) U(k, h+1)=(k+1)(k+2) U(k+2, h)-(k+1) U(k+1, h)+U(k, h)$

$+\sum_{r=0}^{k} \sum_{s=0}^{h}(k-r+1)(k-r+2) U(r, h-s) U(k-r+2, s)-\sum_{r=0}^{k} \sum_{s=0}^{h} U(r, h-s) U(k-r, s)$

The solution of $u(x, t)$ can be found as

$u(x, t)=a e^{x+t}$

With the Maple software, it can be obtained that

$u_{a}(x, t)=a+a t+\frac{a t^{2}}{2}+a x+a x t+\frac{a x t^{2}}{2}+\frac{a x^{2}}{2}+\frac{a x^{2} t}{2}+\frac{a x^{2} t^{2}}{4}+\frac{a x^{3}}{6}+\frac{a x^{3} t}{6}+\frac{a x^{3} t^{2}}{12}+\frac{a x^{4}}{24}$

$+\frac{a x^{4} t}{24}$

$+\frac{a x^{4} t^{2}}{48}$

Let $a \in \operatorname{Beta}(\alpha=2, \beta=1)$

$E(a)=\frac{2}{3}, E\left(a^{2}\right)=\frac{1}{2}$

$u_{a}(x, t)=\left(a+a x+\frac{1}{2} a x^{2}+\frac{1}{6} a x^{3}+\frac{1}{24} a x^{4}\right)+t\left(a+a x+\frac{1}{2} a x^{2}+\frac{1}{6} a x^{3}+\frac{1}{24} a x^{4}\right)+t^{2}\left(\frac{1}{2} a+\frac{1}{2} a x\right.$

$\left.+\frac{1}{4} a x^{2}+\frac{1}{12} a x^{3}+\frac{1}{48} a x^{4}\right)$

$u_{a}(x, t)=a\left(1+x+\frac{x^{2}}{2}+\frac{x^{3}}{6}+\frac{x^{4}}{24}\right)+a t\left(1+x+\frac{x^{2}}{2}+\frac{x^{3}}{6}+\frac{x^{4}}{24}\right)+\frac{a t^{2}}{2}\left(1+x+\frac{x^{2}}{2}+\frac{x^{3}}{6}+\frac{x^{4}}{24}\right)$

$=f(x)\left(a+a t+\frac{a t^{2}}{2}\right)$ 
From (14) equation, $f(x)=\left(1+x+\frac{x^{2}}{2}+\frac{x^{3}}{6}+\frac{x^{4}}{24}\right), \mathrm{X}(0)=a f(x), \mathrm{X}(1)=a f(x), \mathrm{X}(2)=\frac{a f(x)}{2}$ are obtained.

We get the expected value of (14) as follows.

$E\left[u_{a}(x, t)\right]=E\left[f(x)\left(a+a t+a t^{2}\right)\right]=f(x)\left(E(a)+E(a) t+E(a) t^{2}\right)=f(x)\left(\frac{2}{3}+\frac{2 t}{3}+\frac{t^{2}}{3}\right)$

So the expected value of (14) can be obtained that

$E\left[u_{a}(x, t)\right]=\left(1+x+\frac{x^{2}}{2}+\frac{x^{3}}{6}+\frac{x^{4}}{24}\right)\left(\frac{2}{3}+\frac{2 t}{3}+\frac{t^{2}}{3}\right)$

If the Laplace-Padé technique is applied to improve the approximate analytical value obtained for the expected value of equation (11), the following solution is obtained.

$M=\frac{1}{36}\left(24+24 x+12 x^{2}+4 x^{3}+x^{4}\right) e^{t}$

The graph of this solution is given in figure 2 .

\section{E(u)}

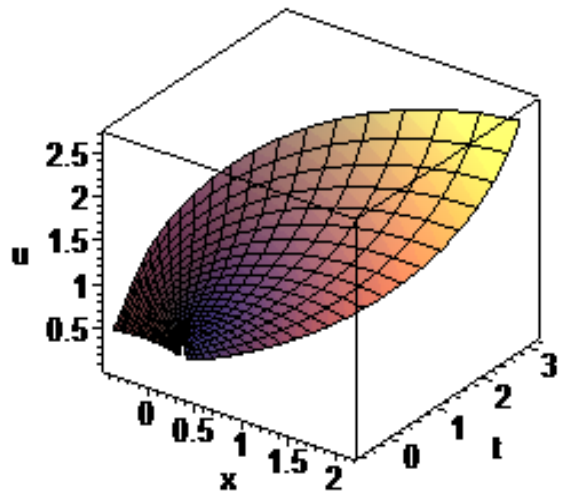

Figure 1. Time-dependent change of expected value of the equation (11)

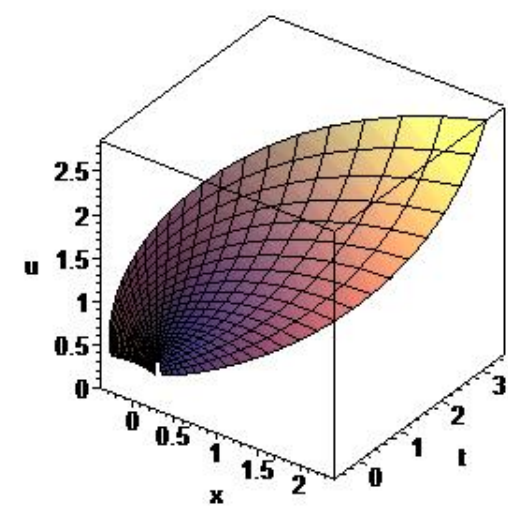

Figure 2. The time-dependent change of the solution of the expected value of the equation (11) from MDTM.

$V\left[u_{a}(x, t)\right]=\sum_{j=0}^{2} \sum_{i=0}^{2} \operatorname{cov}(x(i), x(j)) t^{i+j}$

$\operatorname{cov}(x(i), x(j))=E(x(i) x(j))-E(x(i)) E(x(j))$

If we calculate the variance of (14) with (15) as follows

$V\left[u_{a}(x, t)\right]=\operatorname{cov}(x(0), x(0))+\operatorname{cov}(x(0), x(1)) t+\operatorname{cov}(x(0), x(2)) t^{2}+\operatorname{cov}(x(1), x(0)) t$

$+\operatorname{cov}(x(1), x(1)) t^{2}+\operatorname{cov}(x(1), x(2)) t^{3}+\operatorname{cov}(x(2), x(0)) t^{2}+\operatorname{cov}(x(2), x(1)) t^{3}$

$+\operatorname{cov}(x(2), x(2)) t^{4}$

The variance of (14) can be obtained as 
$V\left[u_{a}(x, t)\right]=\left(1+2 x+2 x^{2}+\frac{4 x^{3}}{3}+\frac{2 x^{4}}{3}+\frac{x^{5}}{4}+\frac{5 x^{6}}{72}+\frac{x^{7}}{72}+\frac{x^{8}}{576}\right)\left(\frac{t^{2}}{9}+\frac{t^{3}}{18}+\frac{t^{4}}{72}\right)$

If the Laplace-Padé technique is applied to improve the approximate analytical value obtained for the variance of the equation (11), the following solution is obtained.

$$
\begin{aligned}
& N=\frac{16}{27} x+\frac{16}{27} x^{2}+\frac{32}{81} x^{3}+\frac{16}{81} x^{4}-\frac{16}{27} e^{\frac{3}{4} t} x \cos \left(\frac{t \sqrt{3}}{4}\right)+\frac{2}{27} x^{5}+\frac{5}{243} x^{6}+\frac{1}{243} x^{7}+\frac{1}{1944} x^{8} \\
& +\frac{8}{27}+\frac{16}{27} e^{\frac{3}{4} t} x \sqrt{3} \sin \left(\frac{t \sqrt{3}}{4}\right)+\frac{16}{27} e^{\frac{3}{4} t} x^{2} \sqrt{3} \sin \left(\frac{t \sqrt{3}}{4}\right)+\frac{32}{81} e^{\frac{3}{4} t} x^{3} \sqrt{3} \sin \left(\frac{t \sqrt{3}}{4}\right) \\
& +\frac{16}{81} e^{\frac{3}{4} t} x^{4} \sqrt{3} \sin \left(\frac{t \sqrt{3}}{4}\right)+\frac{2}{27} e^{\frac{3}{4} t} x^{5} \sqrt{3} \sin \left(\frac{t \sqrt{3}}{4}\right)+\frac{5}{243} e^{\frac{3}{4} t} x^{6} \sqrt{3} \sin \left(\frac{t \sqrt{3}}{4}\right) \\
& +\frac{1}{243} e^{\frac{3}{4} t} x^{7} \sqrt{3} \sin \left(\frac{t \sqrt{3}}{4}\right)+\frac{1}{1944} e^{\frac{3}{4} t} x^{8} \sqrt{3} \sin \left(\frac{t \sqrt{3}}{4}\right)-\frac{16}{27} e^{\frac{3}{4} t} x^{2} \cos \left(\frac{t \sqrt{3}}{4}\right) \\
& -\frac{32}{81} e^{\frac{3}{4} t} x^{3} \cos \left(\frac{t \sqrt{3}}{4}\right)-\frac{16}{81} e^{\frac{3}{4} t} x^{4} \cos \left(\frac{t \sqrt{3}}{4}\right)+\frac{8}{27} e^{\frac{3}{4} t} \sqrt{3} \sin \left(\frac{t \sqrt{3}}{4}\right)-\frac{2}{27} e^{\frac{3}{4} t} x^{5} \cos \left(\frac{t \sqrt{3}}{4}\right) \\
& -\frac{5}{243} e^{\frac{3}{4} t} x^{6} \cos \left(\frac{t \sqrt{3}}{4}\right)-\frac{1}{243} e^{\frac{3}{4} t} x^{7} \cos \left(\frac{t \sqrt{3}}{4}\right)-\frac{1}{1944} e^{\frac{3}{4} t} x^{8} \cos \left(\frac{t \sqrt{3}}{4}\right)-\frac{8}{27} e^{\frac{3}{4} t} \cos \left(\frac{t \sqrt{3}}{4}\right)
\end{aligned}
$$

The graph of this solution is given in figure 4.

\section{$V(u)$}

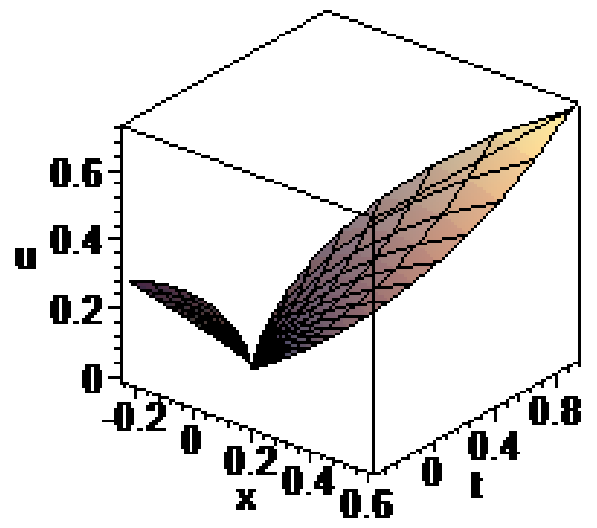

Figure 3. The time-dependent variation of the variance of the equation (11).

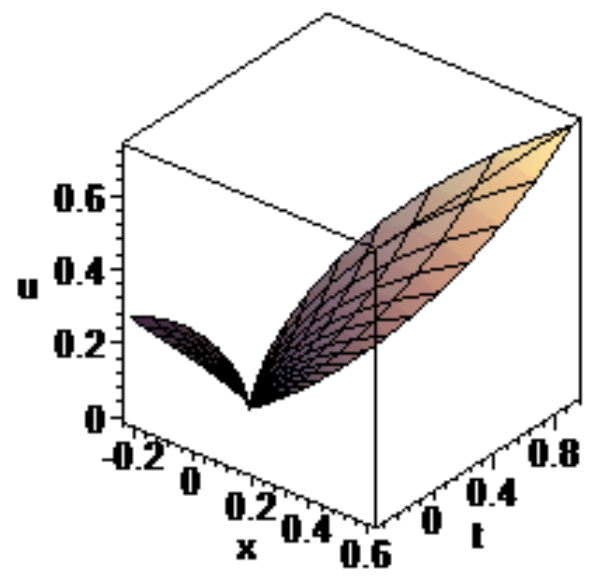

Figure 4. The time-dependent variation of the solution obtained from MDTM of the equation (11)

Example 2. Consider the following Gas Dynamics equation

$\frac{\partial u}{\partial t}=-u \frac{\partial u}{\partial x}-u^{2}+u$

with the initial-value conditions for $a>0$ and let $a$ be random variable with Beta distribution. Let these initial-value conditions be random:

$u(x, 0)=a e^{-x}, u(0, t)=a e^{t}, u_{t}(x, 0)=a e^{-x}, u_{x}(0, t)=-a e^{-t}$ 
Applying the differential transform of (17), it can be found that

$(h+1) U(k, h+1)=-\sum_{r=0}^{k} \sum_{s=0}^{h}(k-r+1) U(r, h-s) U(k-r+1, s)+U(k, h)$

$-\sum_{r=0}^{k} \sum_{s=0}^{h} U(r, h-s) U(k-r, s)$

The solution of $u(x, t)$ can be found as

$u(x, t)=a e^{-x+t}$. Let $a \in \operatorname{Beta}(\alpha=2, \beta=1)$.

$E(a)=\frac{2}{3}, E\left(a^{2}\right)=\frac{1}{2}$

With the Maple software, it can be obtained that

$u_{a}(x, t)=\left(a-a x+\frac{a x^{2}}{2}-\frac{a x^{3}}{6}+\frac{a x^{4}}{24}\right)+t\left(a-a x+\frac{a x^{2}}{2}-\frac{a x^{3}}{6}+\frac{a x^{4}}{24}\right)$

$+t^{2}\left(\frac{a}{2}-\frac{a x}{2}+\frac{a x^{2}}{4}-\frac{a x^{3}}{12}+\frac{a x^{4}}{48}\right)$

$u_{a}(x, t)=a\left(1-x+\frac{x^{2}}{2}-\frac{x^{3}}{6}+\frac{x^{4}}{24}\right)+a t\left(1-x+\frac{x^{2}}{2}-\frac{x^{3}}{6}+\frac{x^{4}}{24}\right)+\frac{a t^{2}}{2}\left(1-x+\frac{x^{2}}{2}-\frac{x^{3}}{6}+\frac{x^{4}}{24}\right)$

$=f(x)\left(a+a t+\frac{1}{2} a t^{2}\right)$

From (20) equaiton, $f(x)=\left(1-x+\frac{x^{2}}{2}-\frac{x^{3}}{6}+\frac{x^{4}}{24}\right), \mathrm{X}(0)=a f(x), \mathrm{X}(1)=a f(x), \mathrm{X}(2)=\frac{1}{2} a f(x)$ are obtained.

We get the expected value of (20) as follows.

$E\left[u_{a}(x, t)\right]=E\left[f(x)\left(a+a t+a t^{2}\right)\right]=f(x)\left[E(a)+E(a) t+E(a) t^{2}\right]=f(x)\left(\frac{2}{3}+\frac{2 t}{3}+\frac{t^{2}}{3}\right)$

So the expected value of (20) can be obtained that

$E\left[u_{a}(x, t)\right]=\left(1-x+\frac{x^{2}}{2}-\frac{x^{3}}{6}+\frac{x^{4}}{24}\right)\left(\frac{2}{3}+\frac{2 t}{3}+\frac{t^{2}}{3}\right)$

$M=\frac{1}{36}\left(24-24 x+12 x^{2}-4 x^{3}+x^{4}\right) e^{t}$

The graph of this solution is given in figure 6 .

\section{$E($ (u)}

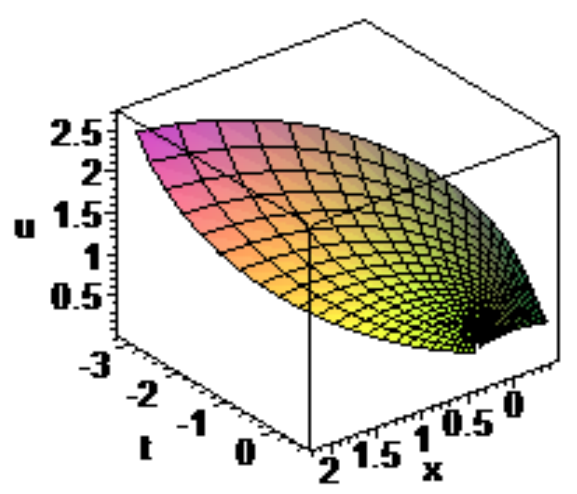

Figure 5. Time-dependent change of expected value of the equation (17)

If the Laplace-Padé technique is applied to improve the approximate analytical value obtained for the expected value of equation (17), the following solution is obtained. 


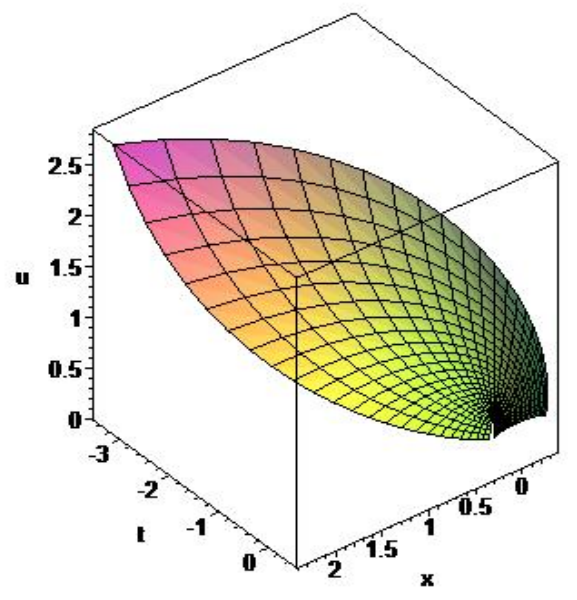

Figure 6. The time-dependent change of the solution of the expected value of the equation (17) from the modified Differential Transformation Method.

$$
\begin{aligned}
& V\left[u_{a}(x, t)\right]=\sum_{j=0}^{2} \sum_{i=0}^{2} \operatorname{cov}(x(i), x(j)) t^{i+j} \\
& \operatorname{cov}(x(i), x(j))=E(x(i) x(j))-E(x(i)) E(x(j))
\end{aligned}
$$

If we calculate variance of (20) with (21),

$$
\begin{aligned}
& V\left[u_{a}(x, t)\right]=\operatorname{cov}(x(0), x(0))+\operatorname{cov}(x(0), x(1)) t+\operatorname{cov}(x(0), x(2)) t^{2}+\operatorname{cov}(x(1), x(0)) t \\
& +\operatorname{cov}(x(1), x(1)) t^{2}+\operatorname{cov}(x(1), x(2)) t^{3}+\operatorname{cov}(x(2), x(0)) t^{2}+\operatorname{cov}(x(2), x(1)) t^{3} \\
& +\operatorname{cov}(x(2), x(2)) t^{4}
\end{aligned}
$$

The variance of (20) can be obtained as

$$
V\left[u_{a}(x, t)\right]=\left(1-2 x+2 x^{2}-\frac{4 x^{3}}{3}+\frac{2 x^{4}}{3}-\frac{x^{5}}{4}+\frac{5 x^{6}}{72}-\frac{x^{7}}{72}+\frac{x^{8}}{576}\right)\left(\frac{t^{2}}{9}+\frac{t^{3}}{18}+\frac{t^{4}}{72}\right)
$$

If the Laplace-Padé technique is applied to improve the approximate analytical value obtained for the variance of the equation (17), the following solution is obtained.

$$
\begin{aligned}
& N=-\frac{16}{27} x+\frac{16}{27} x^{2}-\frac{32}{81} x^{3}+\frac{16}{81} x^{4}+\frac{16}{27} e^{\frac{3}{4} t} x \cos \left(\frac{t \sqrt{3}}{4}\right)-\frac{2}{27} x^{5}+\frac{5}{243} x^{6}-\frac{1}{243} x^{7} \\
& +\frac{1}{1944} x^{8}+\frac{8}{27}-\frac{16}{27} e^{\frac{3}{4} t} x \sqrt{3} \sin \left(\frac{t \sqrt{3}}{4}\right)+\frac{16}{27} e^{\frac{3}{4} t} x^{2} \sqrt{3} \sin \left(\frac{t \sqrt{3}}{4}\right) \\
& -\frac{32}{81} e^{\frac{3}{4} t} x^{3} \sqrt{3} \sin \left(\frac{t \sqrt{3}}{4}\right)+\frac{16}{81} e^{\frac{3}{4} t} x^{4} \sqrt{3} \sin \left(\frac{t \sqrt{3}}{4}\right)-\frac{2}{27} e^{\frac{3}{4} t} x^{5} \sqrt{3} \sin \left(\frac{t \sqrt{3}}{4}\right) \\
& +\frac{5}{243} e^{\frac{3}{4} t} x^{6} \sqrt{3} \sin \left(\frac{t \sqrt{3}}{4}\right)-\frac{1}{243} e^{\frac{3}{4} t} x^{7} \sqrt{3} \sin \left(\frac{t \sqrt{3}}{4}\right)+\frac{1}{1944} e^{\frac{3}{4} t} x^{8} \sqrt{3} \sin \left(\frac{t \sqrt{3}}{4}\right) \\
& -\frac{16}{27} e^{\frac{3}{4} t} x^{2} \cos \left(\frac{t \sqrt{3}}{4}\right)+\frac{32}{81} e^{\frac{3}{4} t} x^{3} \cos \left(\frac{t \sqrt{3}}{4}\right)-\frac{16}{81} e^{\frac{3}{4} t} x^{4} \cos \left(\frac{t \sqrt{3}}{4}\right)+\frac{8}{27} e^{\frac{3}{4} t} \sqrt{3} \sin \left(\frac{t \sqrt{3}}{4}\right) \\
& +\frac{2}{27} e^{\frac{3}{4} t} x^{5} \cos \left(\frac{t \sqrt{3}}{4}\right)-\frac{5}{243} e^{\frac{3}{4} t} x^{6} \cos \left(\frac{t \sqrt{3}}{4}\right)+\frac{1}{243} e^{\frac{3}{4} t} x^{7} \cos \left(\frac{t \sqrt{3}}{4}\right)
\end{aligned}
$$


$-\frac{1}{1944} e^{\frac{3}{4} t} x^{8} \cos \left(\frac{t \sqrt{3}}{4}\right)-\frac{8}{27} e^{\frac{3}{4} t} \cos \left(\frac{t \sqrt{3}}{4}\right)$

The graph of this solution is given in figure 8 .

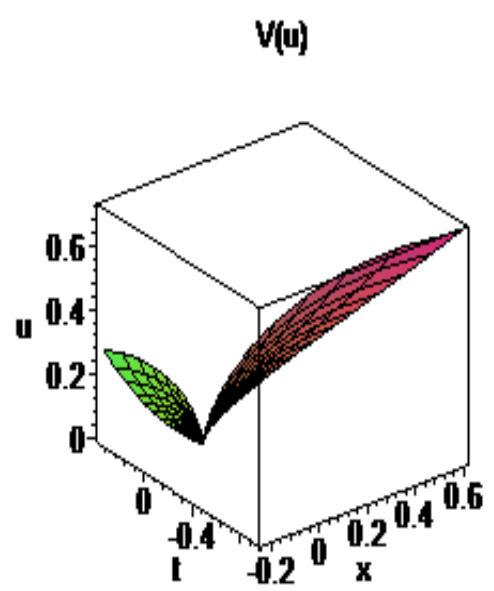

Figure 7. The time-dependent variation of the variance of the equation (17)

\section{Conclusion}

In this study, we analyzed some random component partial differential equations containing random initial values. We obtained approximate analytical solutions of these equations with random Differential Transformation Method (rDTM). We obtained approximate variance and expected values with for the examples by using rDTM. We applied the modified rDTM (Pade-DTM) technique to improve the results and to extend the convergence region. Graphics simulations were given for solutions. Comparison of the approximate solution with the $M$ function improved from expected

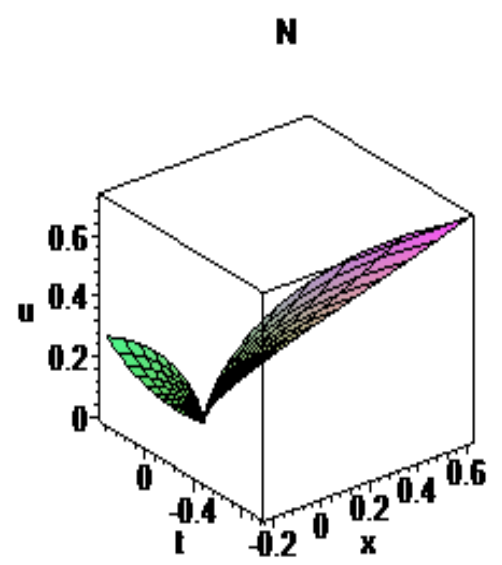

Figure 8. The time-dependent variation of the solution obtained from modified Differential Transformation Method for the equation (17)

value of approximate solution and the error between these values for example 1 is given in Table2. Comparison of the approximate solution with the $M$ function improved from expected value of approximate solution and the error between these values for example 2 is given in Table3.

It is observed that error between the approximate solution with the $M$ function obtained from expected value of approximate solution is respectively small for example 1 and example 2 from Table 2 and Table 3.

Table2: Comparison of the approximate solution with the $M$ function obtained from expected value of approximate solution for example 1 .

\begin{tabular}{|r|r|r|r|r|}
\hline$x$ & $t$ & $u_{a}(x, t)\left(a=\frac{2}{3}\right)$ & $M$ & Err= $\left|u_{a}(x, t)-M\right|$ \\
\hline-1.0 & -1.0 & 0.1250000000 & 0.0919686029 & 0.0333313971 \\
\hline-0.8 & -0.8 & 0.1566008889 & 0.1353179138 & 0,0212829751 \\
\hline-0.6 & -0.6 & 0.2124346667 & 0.2010114086 & 0,0114232581 \\
\hline-0.4 & -0.4 & 0.3039146667 & 0.2995883725 & 0,0043262942 \\
\hline-0.2 & -0.2 & 0.4475742223 & 0.4468814390 & 0,0006927833 \\
\hline 0.0 & 0.0 & 0.6666666666 & 0.6666666666 & 0,0000000000 \\
\hline 0.2 & 0.2 & 0.9934053333 & 0.9945475525 & 0,0009422192 \\
\hline 0.4 & 0.4 & 1.4718435570 & 1.4836030860 & 0,0117595290 \\
\hline 0.6 & 0.6 & 2.1613946670 & 2.2125381220 & 0,0511434550 \\
\hline 0.8 & 0.8 & 3.1409920000 & 3.2973614390 & 0,1569694390 \\
\hline 1.0 & 1.0 & 4.5138888888 & 4.9080088569 & 0,3941199681 \\
\hline
\end{tabular}


Table3: Comparison of the approximate solution with the $M$ function obtained from expected value of approximate solution for example 2 .

\begin{tabular}{|r|r|r|r|r|}
\hline$x$ & $t$ & $u_{a}(x, t)\left(a=\frac{2}{3}\right)$ & $M$ & Err= $\left|u_{a}(x, t)-M\right|$ \\
\hline-1.0 & -1.0 & 0.9027777777 & 0.6642267687 & 0.2385510090 \\
\hline-0.8 & -0.8 & 0.7704320000 & 0.6657257932 & 0.1047062068 \\
\hline-0.6 & -0.6 & 0.7042746667 & 0.6664036762 & 0.0378709905 \\
\hline-0.4 & -0.4 & 0.6762524447 & 0.6666258378 & 0.0096266069 \\
\hline-0.2 & -0.2 & 0.6676986667 & 0.6666651613 & 0.0010335054 \\
\hline 0.0 & 0.0 & 0.6666666666 & 0.66666666666 & 0.0000000000 \\
\hline 0.2 & 0.2 & 0.6659031112 & 0.6666687676 & 0.0007656564 \\
\hline 0.4 & 0.4 & 0.6614613333 & 0.6667461850 & 0.0052848517 \\
\hline 0.6 & 0.6 & 0.6519546667 & 0.6673813792 & 0.0154267125 \\
\hline 0.8 & 0.8 & 0.6384497779 & 0.6702340147 & 0.0317842368 \\
\hline 1.0 & 1.0 & 0.6250000000 & 0.6795704571 & 0.0545704571 \\
\hline
\end{tabular}

\section{References}

Abassy, T.A., El-Tawil, M.A. and El-Zoheiry, H., 2007. Exact Solutions of Some Nonlinear Partial Differential Equations Using the Variational Iteration Method Linked with Laplace Transforms and the Pade Technique. Computers and Mathematics with Applications, 54, 940-954.

Bildik, N., Konuralp, A., Bek, F.O. and Küçükarslan, S., 2006. Solution of Different Type of the Partial Differential Equation by Differential Transform Method and Adomian's Decomposition Method. Applied Mathematics and Computation, 172(1), 551-567.

Eugene, N., Lee, C. and Femoye, F., 2002. BetaNormal Distribution and Its Applications. Communications in Statistics-Theory and Methods, 31(4), 497-512.

Hadizadeh, M. and Moatamedi, N., 2007. A New Differential Transformation Approach for Two-Dimensional Volterra Integral Equations, International Journal of Computer Mathematics, 84(4), 515-526.

Jang, M.J., Chen, C.L. and Liu, Y.C., 2001. TwoDimensional Differential Transform for Partial Differential Equations. Applied Mathematics and Computation, 121(2-3), 261-270.

Kangalgil, F. and Ayaz, F., 2009. Solitary Wave Solutions for the $\mathrm{KdV}$ and $\mathrm{mKdV}$ Equations by Differential Transform Method. Chaos, Solitons and Fractals, 41, 464-472.
Kanth, R.A.S.V. and Aruna, K., 2009. TwoDimensional Differential Transform Method for Solving Linear and Non-linear Schrödinger Equations. Chaos, Solitons and Fractals, 41, 2277-2281.

Khalaf, S.L., 2011. Mean Square Solutions of Second-Order Random Differential Equations by Using Homotopy Perturbation Method. International Mathematical Forum, 6, 2361-2370.

Khudair, A.R., Ameen, A.A. and Khalaf, S.L., 2011. Mean Square Solutions of SecondOrder Random Differential Equations by Using Adomian Decomposition Method. Applied Mathematical Sciences, 5, 25212535.

Khudair, A.R., Ameen, A.A. and Khalaf, S.L., 2011. Mean Square Solutions of SecondOrder Random Differential Equations by Using Variational Iteration Method. Applied Mathematical Sciences, 5, 25052519.

Khudair, A.R., Haddad, S.A.M. and Khalaf, S.L., 2016. Mean Square Solutions of SecondOrder Random Differential Equations by Using the Differential Transformation Method. Open Journal of Applied Sciences, 6, 287-297.

Merdan, M., 2010. A New Application of Modified Differential Transformation Method for Modelling the Pollution of a System of Lakes. Selçuk Journal of Applied Mathematics, 11(2), 27-40. 
Pukhov, G.E., 1982. Differential Transforms and Circuit Theory. Circuit Theory and Applications. 10, 265-276.

Tari, A., Rahimi, M.Y., Shahmorad, S. and Talati, F., 2009. Solving a Class of TwoDimensional Linear and Nonlinear Volterra Integral Equaitons by the Differential Transform Method. Journal of Computational and Applied Mathematics, 228, 70-76.

Villafuerte, L. and Chen-Charpentier, B.M., 2012. A Random Differential Transform Method: Theory and Applications, Applied Mathematics Letters, 25(10), 1490-1494.
Yüzbaşi, Ş. and Ismailov, N., 2017. Differential Transform Method to Solve TwoDimensional Volterra Integral Equations with Proportional Delays. New Trends in Mathematical Sciences, 5(4), 65-71.

Zhou, J.K., 1986. Differential Transformation and Its Applications for Electrical Circuits, Huazhong University Press, Wuhan.

Ziyaee, F. and Tari, A., 2015. Differential Transform Method for Solving the TwoDimensional Fredholm Integral Equations. Applications and Applied Mathematics, 10(2), 852-863. 